\title{
Post-collection Separation of Plastic Waste: Better for the Environment and Lower Collection Costs?
}

\author{
Elbert Dijkgraaf ${ }^{1}$ (D) $\cdot$ Raymond Gradus $^{2}$
}

Accepted: 9 July 2020 / Published online: 16 July 2020

(c) The Author(s) 2020

\begin{abstract}
The European Union advocates a plastic waste recycling rate of more than 55\%. Even for the Netherlands, which has already invested heavily in recycling plastic waste of households, it will still be a challenge to meet this target. The preferred solution to fulfil this target in the Netherlands is implementing separate collection schemes at the curbside, although some municipalities invested in post-separation. We show, based on data for 2013-2014, that post-collection separation is an advisable alternative, with an increased separation of plastic waste compared with home separation. This is even slightly the case if home separation is combined with a unit-based pricing system for unsorted waste and with a frequent door-to-door collection of plastic waste. Moreover, there are indications that the cost effectiveness of recycling plastic waste increases if post separation is chosen. In addition, some claim that unit-based pricing of unsorted waste is important to create an awareness effect to buy less packaging material. However, based on the combination of post separation and unit-based pricing, we have no indication for such awareness effect as the price effect on the amount of plastic waste is insignificantly small.
\end{abstract}

Keywords Plastic waste $\cdot$ Recycling $\cdot$ Post separation $\cdot$ Home separation $\cdot$ Cost effectiveness

\section{Introduction}

European waste policy focuses on the separation of waste by households. According to the EU, $60 \%$ of municipal waste should be separated in 2030. The Netherlands is adding a considerable amount to this by demanding that $75 \%$ should be recycled in 2020 and that every inhabitant should be allowed to have only $100 \mathrm{~kg}$ of unsorted waste per year in 2020 and

Elbert Dijkgraaf

dijkgraaf@ese.eur.nl

Raymond Gradus

r.h.j.m.gradus@vu.nl

1 Erasmus School of Economics, Tinbergen Institute, Erasmus University Rotterdam, Rotterdam, The Netherlands

2 Faculty of Economics and Business Administration, Tinbergen Institute, VU University Amsterdam, Amsterdam, The Netherlands 
limiting this to only $30 \mathrm{~kg}$ in 2025 . To achieve this goal, separation and recycling of glass, paper/carton, plastic and metals are crucial. In recent decades, the use of plastic packaging has increased substantially and therefore also the efforts to recycle it (Hopewell et al. 2009). For plastic the EU-target for re-use of plastic packaging is 55\% by 2030 (EC 2017). Moreover, for plastic (packaging) waste the Netherlands recycled 51\% in 2016.

The preferred solution in the Netherlands to fulfil this target is separate collection systems at the curbside as this is far more common than post-collection separation. Most municipalities have an advanced system of curbside collection of unsorted waste and recyclables and easily assessable bring locations for bottles, paper and plastics ${ }^{1}$ (Dijkgraaf and Gradus 2017). In addition, more and more Dutch municipalities introduce unit-based pricing (UBP) systems for waste, as these unit-based pricing systems are effective in reducing unsorted waste and stimulating recycling. By 2017, 45\% of all Dutch municipalities had implemented a unit-based pricing system, this share has risen substantially from $16 \%$ in 1999 (Gradus and Dijkgraaf 2019). However, unit-based pricing systems can have some adverse effects as illegal dumping or waste tourism (Fullerton and Kinnaman 1996). The debate on the impact of waste fees on illegal disposal or waste tourism is still open as data are not readily available. Interestingly, for Switzerland there are two recent opposing indications. Erhardt (2019) investigates whether the introduction of a unit-based garbage fee induces waste dumping in nearby communities which do not implement such a policy and call it a "waste haven effect". Interestingly, he found some evidence for waste havens in a cross-section of 1752 Swiss municipalities. By contrast, in the Swiss city of Lausanne, Carattini et al. (2018) show that 4 years after the introduction of a unit-based pricing system, illegal disposal remained a minor issue.

Interestingly, some municipalities especially in the north of the Netherlands have invested in post-collection or mechanical separation of plastic waste (hereafter 'post separation'). Instead of sorting plastic waste out at home, plastics are collected together with mixed waste streams and separated in a factory (see Feil et al. 2017). ${ }^{2}$ Dutch recycling companies have innovated with infrared and filmgrabber techniques to separate plastics from mixed waste, and these methods seem to be effective. Owners of these factories claim that they can sort out more plastic than people do at home. In this paper, we use recent data from Dutch municipalities to test this claim of more effective post-collection separation of plastic waste, which has not been examined in the literature until now. Based on data for 2013 and 2014 for all Dutch municipalities, we investigate in this paper whether municipalities with post separation produce more separated household plastic waste in kilograms. With detailed data for frequency of curbside collection and type of container, we are able to test also whether these variables influence the quantity of collected plastic. It could be the case that on average post separation performs better, but not if curbside collection is optimized by collection method and frequency. Moreover, we include interaction effects if a municipality chooses to have both UBP and post separation. The possibilities for households to separate plastic waste from unsorted waste are non-existent in this case, but there can be an effect on total quantity of plastics due to buying products with less plastics. Earlier contributions claimed that unit-based pricing of unsorted waste is important to create

\footnotetext{
1 In recent years, some municipalities combine home separation of plastic waste with metal packages and beverage cartons.

2 As Feil et al. (2017) describes there were two large factories in the north of the Netherlands (one in Wijster and one in Oude Haske) that use the near infrared sorter to select plastic waste. In 2018, new factories have opened in large cities as Rotterdam and Amsterdam.
} 
an awareness effect which may lead consumers to purchase goods with less packaging (see for an overview Dijkgraaf and Gradus 2014). Our paper adds to the literature as it is the first to test if there are awareness effects for plastic packaging, although this test is only indirect. However, unit-based pricing can also have a negative effect on the motivation effect of people to sort waste, for people who are already normative motivated and who are annoyed by the introduction of unit-based pricing. In an empirical investigation for a town in Norway, Heller and Vatn (2017) show that half of the people behave in that direction. Moreover, illegal and illicit dumping increases if a fee is introduced.

The relative performance of post separation is not only interesting from an environmental point of view, but also from a financial perspective. Home separation of plastic waste is quite expensive as it demands a separate collection infrastructure and storage and transport of low-density volumes (Gradus et al. 2017). For the Netherlands, the infrastructure costs for the collection and home separation of household plastic strongly outweigh the revenues that are generated from the sale of recycled plastic. Therefore, a municipality is compensated for this deficit by the packaging industry and in 2015 it received a contribution of $€$ 677 per metric ton of collected household plastic waste. In Gradus et al. (2017) we calculate the implicit price of 1 metric ton of $\mathrm{CO}_{2}$ reduction by means of plastic home separation and recycling (compared with incineration) and show that it is equal to $€ 178$. In general, this implicit price is much higher than current (or historic) $\mathrm{CO}_{2}$ prices in the EU Emissions Trading System or the estimated external costs of $\mathrm{CO}_{2}$ emissions or alternatives to reduce $\mathrm{CO}_{2}$ emissions (e.g. renewable energy). A sensitivity analysis shows that this conclusion is robust. This calculation is based on the mass balance of home-separated plastic waste from households. The recycling rate for this collected mixed plastic is $75 \%$, meaning that $25 \%$ of the collected household plastic is still used for energy recovery (as in the Netherlands unsorted waste is incinerated). The advantage of post-separation is that it is not needed to separate these 'polluted' and ultimately burned plastics, but a large investment to build a plant is needed. Therefore, in this paper we discuss not only the relative effectiveness of post separation in the quantity of plastic waste, but also in economic terms. As far as we know the cost effectiveness of post versus home separation has not been examined in the literature until now. Based on empirical evidence, there are indications that homeseparated plastic waste is of lower quality than plastic waste from post separation (Brouwer et al. 2018). Therefore, in a sensitivity analysis we discuss whether our conclusions change if the quality of secondary plastics increases due to post separation and if the recycling rate goes up.

The paper is organized as follows. In Sect. 2, data and method are discussed. Estimation results are given in Sect. 3. In Sect. 4 we discuss a break-even analysis for the cost effectiveness of post separation versus home separation. Finally, Sect. 5 contains some conclusions and suggestions for future research.

\section{Data and Method}

Data on the amount of separated plastic waste by type of separation for (nearly) all Dutch municipalities in 2013 and 2014 come from Afvalfonds Verpakkingen. Furthermore, data on different collection methods come from Statistics Netherlands. We have data for 404 
Table 1 Share of municipalities with different plastic waste separation systems

\begin{tabular}{llllcc}
\hline Separation method & Post & Curb & Bring & $2013(\%)$ & $2014(\%)$ \\
\hline Post (PS) & 1 & 0 & 0 & 11 & 11 \\
Curbside (CS) & 0 & 1 & 0 & 32 & 28 \\
Bring (BS) & 0 & 0 & 1 & 22 & 18 \\
Post and curbside (PCS) & 1 & 1 & 0 & 4 & 7 \\
Post and bring (PBS) & 1 & 0 & 1 & 1 & 4 \\
Curbside and bring (CBS) & 0 & 1 & 1 & 24 & 23 \\
Post, curbside and bring (PCBS) & 1 & 1 & 1 & 4 & 7 \\
None & 0 & 0 & 0 & 2 & 1 \\
\hline
\end{tabular}

municipalities with a total of 778 observations. ${ }^{3}$ Total recycled plastic waste is on average 11 kilograms $(\mathrm{kg})$ per inhabitant (see "Appendix" for the variable definitions). There are large differences in plastic separation between Dutch municipalities. In 2013-2014, the four largest cities in the Netherlands (i.e. Amsterdam, the Hague, Rotterdam and Utrecht) separated on average 1-2 kg, while some rural municipalities collect $30 \mathrm{~kg}$ per inhabitant yearly. ${ }^{4}$ Interestingly, the average amount of separated plastic per inhabitant increased from $9 \mathrm{~kg}$ in 2013 to $13 \mathrm{~kg}$ in 2014. This is interesting as in 2014 post-collection separation is more mature than in 2013. Thus this rise gives already a first indication of a positive effect of post-collection separation.

In Table 1 the share of the different separation systems in 2013 and 2014 are given. We distinguish between three separation systems (post, curbside and bring) and also combinations are possible.

In 2013-2014, 11\% of the Dutch municipalities have only post separation for their plastic waste. In approximately $30 \%$ of municipalities there is a system of only curbside collection of plastic waste, and approximately $20 \%$ of Dutch municipalities have a system of only bring locations. Some of these municipalities combine different systems. The most important combination is curbside collection and bring locations, accounting for $23-24 \%$ of municipalities. A small number of municipalities combine post separation with curbside collection (4-7\%) or with bring separation (1-4\%), or even with both (4-7\%). In our estimations these different systems are included defined as dummies, as shown in Table 1 (with none as a benchmark).

First, we model the amount of (separated) plastic per inhabitant as a function of the separation system and socio-economic variables such as household size, population density, share of elderly people and ethnicity, ${ }^{5}$ as follows:

$$
\begin{aligned}
P L_{i t}=\alpha_{0} & +\lambda_{1} P S_{i t}+\lambda_{2} C S_{i t}+\lambda_{3} B S_{i t}+\lambda_{4} P C S_{i t}+\lambda_{5} P B S_{i t}+\lambda_{6} C B S_{i t} \\
& +\lambda_{7} P C B S_{i t}+\beta_{1} H S_{i t}+\beta_{2} P D_{i t}+\beta_{3} E L_{i t}+\beta_{4} E T_{i t}+\pi_{14}+\varepsilon_{i t},
\end{aligned}
$$

\footnotetext{
${ }^{3}$ For 2013 and 2014 there are respectively 408 and 403 municipalities. In 2013 we have 401 observations and in 2014377 observations. So, we have information for almost all municipalities.

4 This comes close to the maximum plastic packaging production per individual (KIDV 2016).

5 The data on socio-economic variables and on collection methods come from Statistics Netherlands (CBS).
} 
Table 2 Descriptive statistics

\begin{tabular}{|c|c|c|c|c|}
\hline & Mean & Min & $\operatorname{Max}$ & SD \\
\hline Plastic waste per inhabitant & 11.11 & 0 & 29.80 & 5.45 \\
\hline Only post separation & 0.11 & 0 & 1 & 0.31 \\
\hline Extra effect 2014 & 0.06 & 0 & 1 & 0.23 \\
\hline With UBP & 0.02 & 0 & 1 & 0.15 \\
\hline Only curbside collection & 0.30 & 0 & 1 & 0.46 \\
\hline Extra effect 2014 & 0.13 & 0 & 1 & 0.34 \\
\hline With UBP & 0.18 & 0 & 1 & 0.39 \\
\hline Frequency & 6.42 & 0 & 52 & 10.96 \\
\hline Only bring separation & 0.20 & 0 & 1 & 0.40 \\
\hline Extra effect 2014 & 0.09 & 0 & 1 & 0.28 \\
\hline With UBP & 0.04 & 0 & 1 & 0.21 \\
\hline Curbside and post separation & 0.05 & 0 & 1 & 0.23 \\
\hline Extra effect 2014 & 0.03 & 0 & 1 & 0.18 \\
\hline With UBP & 0.03 & 0 & 1 & 0.18 \\
\hline Frequency & 0.95 & 0 & 64 & 4.70 \\
\hline Bring and post separation & 0.03 & 0 & 1 & 0.16 \\
\hline Extra effect 2014 & 0.02 & 0 & 1 & 0.14 \\
\hline With UBP & 0.01 & 0 & 1 & 0.11 \\
\hline Curbside and bring separation & 0.24 & 0 & 1 & 0.42 \\
\hline Extra effect 2014 & 0.11 & 0 & 1 & 0.32 \\
\hline With UBP & 0.09 & 0 & 1 & 0.29 \\
\hline Frequency & 4.73 & 0 & 52 & 9.29 \\
\hline Curbside, bring and post separation & 0.06 & 0 & 1 & 0.24 \\
\hline Extra effect 2014 & 0.04 & 0 & 1 & 0.19 \\
\hline With UBP & 0.02 & 0 & 1 & 0.15 \\
\hline Frequency & 1.05 & 0 & 52 & 4.77 \\
\hline No separation system (none) & 0.01 & 0 & 1 & 0.12 \\
\hline Bag collection & 0.55 & 0 & 1 & 0.50 \\
\hline Duo-bin collection & 0.01 & 0 & 1 & 0.12 \\
\hline Mini-bin collection & 0.06 & 0 & 1 & 0.24 \\
\hline Crate collection & 0.03 & 0 & 1 & 0.16 \\
\hline Household size & 2.36 & 1.67 & 3.41 & 0.18 \\
\hline Population density & 0.72 & 0.00 & 5.21 & 0.88 \\
\hline Inhabitants $65+$ & 19.65 & 8.72 & 31.44 & 3.11 \\
\hline Ethnicity & 5.81 & 0.94 & 37.23 & 5.35 \\
\hline D2014 & 0.48 & 0 & 1 & 0.50 \\
\hline
\end{tabular}

where $\mathrm{PL}_{\mathrm{it}}$ is the plastic amount in kilograms per inhabitant of municipality $\mathrm{i}$ in year $\mathrm{t}, \mathrm{HS}$ is the household size, PD is the population density, EL is the share of elderly people (above 65 years) and ET is ethnicity, defined as the share of non-western people. Finally, $\pi_{14}$ is the year dummy for 2014 and $\varepsilon_{\text {it }}$ is the error term. Table 2 contains all descriptive statistics.

We also estimate alternative models. As post separation became fully active in the course of 2013, it might be better to take the 2014 effect to understand the current effectiveness of post separation. Therefore, in the second model, we multiply the separation 
variables by the year dummy for 2014. Moreover, we would expect the post separation coefficient for this 2014 dummy to be positive. The equation becomes:

$$
\begin{aligned}
P L_{i t}=\alpha_{0} & +\lambda_{1} P S_{i t}+\gamma_{1} \pi 14 P S_{i t}+\lambda_{2} C S_{i t}+\gamma_{2} \pi 14 C S_{i t}+\lambda_{3} B S_{i t}+\gamma_{3} \pi 14 B S_{i t} \\
& +\lambda_{4} P C S_{i t}+\gamma_{4} \pi 14 P C S_{i t}+\lambda_{5} P B S_{i t}+\gamma_{5} \pi 14 P B S_{i t}+\lambda_{6} C B S_{i t}+\gamma_{6} \pi 14 C B S_{i t} \\
& +\lambda_{7} P C B S_{i t}+\gamma_{7} \pi 14 P C B S_{i t}+\beta_{1} H S_{i t}+\beta_{2} P D_{i t}+\beta_{3} E L_{i t}+\beta_{4} E T_{i t}+\varepsilon_{i t} .
\end{aligned}
$$

In the Netherlands, municipalities charge households for waste collection and separation. But the way citizens pay for mixed waste collection differs by Dutch municipality (Dijkgraaf and Gradus 2014, 2015). In most Dutch municipalities, 59\% in 2013-2014, a flat-rate system is used. In other municipalities, a UBP system is used for mixed or unsorted waste. ${ }^{6}$ This introduces a marginal price that provides an incentive to reduce the quantity of waste and to sort plastic waste better. Thus, with UBP, it is expected that municipalities collect less priced unsorted waste and more unpriced plastic waste. UBP can be important to create an awareness effect to purchase goods with less packaging but there can be a negative effect as well if motivation erodes (see also Heller and Vatn 2017). 60\% of municipalities with only a curbside collection system also have UBP, while this is only $18 \%$ for municipalities with only post separation. ${ }^{7}$ For municipalities with only a bring separation system this is $20 \%$. Therefore, we include interaction effects if a municipality chooses to have both UBP and a specific separation system (with the flat-rate system as benchmark). Even if UBP is combined with post separation an extra effect might occur. The possibilities for households to influence the separation of plastic waste directly are non-existent in this case, but there can be an indirect effect on total quantity due to buying products with less plastics (see also D'Amato et al. 2016). Thus, the estimated coefficient for the combination of post-separation and UBP is very interesting. A significant effect of this combination indicates an awareness effect. For home-separation the total effect is the sum of the awareness effect and the effect on better sorting. Having both information on post-separation and UBP makes it possible to have a test of the awareness effect. The equation now becomes:

$$
\begin{aligned}
P L_{i t}=\alpha_{0} & +\lambda_{1} P S_{i t}+\gamma_{1} \pi 14 P S_{i t}+\delta_{1} P S U B_{i t}+\lambda_{2} C_{i t}+\gamma_{2} \pi 14 C S_{i t}+\delta_{2} C S U B_{i t} \\
& +\lambda_{3} B S_{i t}+\gamma_{3} \pi 14 B S_{i t}+\delta_{3} B S U B_{i t}+\lambda_{4} P C S_{i t}+\gamma_{4} \pi 14 P C S_{i t}+\delta_{4} P C S U B_{i t}+\lambda_{5} P B S_{i t} \\
& +\gamma_{5} \pi 14 P B S_{i t}+\delta_{5} P B S U B_{i t}+\lambda_{6} C B S_{i t}+\gamma_{6} \pi 14 C B S_{i t}+\delta_{6} C B S U B_{i t}+\lambda_{7} P C B S_{i t} \\
& +\gamma_{7} \pi 14 P C B S_{i t}+\delta_{7} P C B S U B_{i t}+\beta_{1} H S_{i t}+\beta_{2} P D_{i t}+\beta_{3} E L_{i t}+\beta_{4} E T_{i t}+\varepsilon_{i t}
\end{aligned}
$$

Fourth, we test whether differences in the frequency of curbside collection of plastic waste influence the results. Abbott et al. (2011) show for the UK that there is some evidence that a higher collection frequency of recyclables increases the amount of these materials. Although for the Netherlands the effectiveness of increasing frequency of curbside collection for recyclables has been disputed, in recent years the frequency of collecting plastic waste increased on average in Dutch municipalities (Dijkgraaf and Gradus 2017).

\footnotetext{
${ }^{6}$ Hereby we can distinguish between four different systems - volume, frequency, bag and weight basedwith different incentive structures (Dijkgraaf and Gradus 2014, 2015). We are interested in the interaction between different separation methods and UBP systems, and due to data limitations we are not able to distinguish between these different UBP systems.

7 This follows from Table 2. Only curbside collection is 0.3 and from this 0.18 with UBP, so that $0.18 / 0.3$ (i.e. $60 \%$ ) have a UBP system. Only post separation is 0.11 and from this 0.02 with UBP, so that $0.02 / 0.11$ (i.e. $18 \%$ ) have a UBP system.
} 
On average the number of times a year plastic waste is collected at the curbside is 22 for municipalities with a home separation system. ${ }^{8}$ If curbside collection is combined with post separation, waste is less frequently collected, at 19 times a year on average. ${ }^{9}$ The equation becomes:

$$
\begin{aligned}
P L_{i t}=\alpha_{0} & +\lambda_{1} P S_{i t}+\gamma_{1} \pi 14 P S_{i t}+\delta_{1} P S U B_{i t}+\lambda_{2} C S_{i t}+\gamma_{2} \pi 14 C S_{i t}+\delta_{2} C S U B_{i t} \\
& +\theta_{2} C S F R_{i t}+\lambda_{3} B S_{i t}+\gamma_{3} \pi 14 B S_{i t}+\delta_{3} B_{S U B_{i t}}+\lambda_{4} P C S_{i t}+\gamma_{4} \pi 14 P C S_{i t} \\
& +\delta_{4} P C S U B_{i t}+\theta_{4} P C S F R_{i t}+\lambda_{5} P B S_{i t}+\gamma_{5} \pi 14 P B S_{i t}+\delta_{5} P B S U B_{i t} \\
& +\lambda_{6} C B S_{i t}+\gamma_{6} \pi 14 C B S_{i t}+\delta_{6} C B S U B_{i t}+\theta_{6} C B S F R_{i t}+\lambda_{7} P C B S_{i t} \\
& +\gamma_{7} \pi 14 P C B S_{i t}+\delta_{7} P C B S U B_{i t}+\theta_{7} P C B S F R_{i t}+\beta_{1} H S_{i t}+\beta_{2} P D_{i t} \\
& +\beta_{3} E L_{i t}+\beta_{4} E T_{i t}+\varepsilon_{i t},
\end{aligned}
$$

where $F R_{i t}$ is a variable that denotes the number of times in a year curbside collection takes place. Notice that we only take into account the frequency effect if there is curbside collection.

Fifth, we have information on the type of container that is used for curbside collection of plastic waste. A bag is the most popular (55\%) for the collection of plastic waste. Other types of containers are duo-bins (with other recyclable material such as glass) (1\%), minibins (6\%) and crates (3\%). In Dijkgraaf and Gradus (2017) it was shown that a separate bag or a bin for plastic waste increases the amount of plastics recycled. For other container types, no clear pattern arises. In the Netherlands, municipalities supply bags, crates, duobins or mini-bins. We include dummies for the last three types with the bag system as benchmark. So finally, we estimate:

$$
\begin{aligned}
P L_{i t}=\alpha_{0} & +\lambda_{1} P S_{i t}+\gamma_{1} \pi 14 P S_{i t}+\delta_{1} P S U B_{i t}+\lambda_{2} C S_{i t}+\gamma_{2} \pi 14 C S_{i t}+\delta_{2} C S U B_{i t} \\
& +\theta_{2} C S F R_{i t}+\lambda_{3} B S_{i t}+\gamma_{3} \pi 14 B S_{i t}+\delta_{3} B S U B_{i t}+\lambda_{4} P C S_{i t}+\gamma_{4} \pi 14 P C S_{i t} \\
& +\delta_{4} P C S U B_{i t}+\theta_{4} P C S F R_{i t}+\lambda_{5} P B S_{i t}+\gamma_{5} \pi 14 P B S_{i t}+\delta_{5} P B S U B_{i t}+\lambda_{6} C B S_{i t} \\
& +\gamma_{6} \pi 14 C B S_{i t}+\delta_{6} C B S U B_{i t}+\theta_{6} C B S F R_{i t}+\lambda_{7} P C B S_{i t}+\gamma_{7} \pi 14 P C B S_{i t} \\
& +\delta_{7} P C B S U B_{i t}+\theta_{7} P C B S F R_{i t}+\sum_{j=1}^{3} \kappa_{j} C R_{j i t}+\beta_{1} H S_{i t}+\beta_{2} P D_{i t}+\beta_{3} E L_{i t}+\beta_{4} E T_{i t}+\varepsilon_{i t},
\end{aligned}
$$

where $C R_{j}$ is a vector of dummies which indicates the use of container type $\mathrm{j}$ (mini-bin, duo-bin, bag or crate).

\section{Results}

Table 3 contains our estimation results for Eqs. (1)-(5). All estimations are based on pooled ordinary least squares (OLS) with VCE Robust estimator to correct for clustered standard errors. ${ }^{10}$

\footnotetext{
${ }^{8}$ This follows from Table 2. Only curbside collection is 0.3 and the frequency on average is 6.42 , so that 22 (i.e. 6.42/0.3) is the frequency for this group.

${ }^{9}$ This follows from Table 2. The mean of curbside and post is 0.05 and the frequency on average is 0.95 , so that 18 (i.e. $0.95 / 0.05$ ) is the frequency for this group.

${ }^{10}$ It will be assumed that the standard errors for each municipality are not independently and identically distributed, that there is unknown correlation in $\varepsilon_{i t}$ between the same municipality, but that municipality $i$ and $j$ do not have correlated errors (see Nichols and Schaffer 2007).
} 
Table 3 Estimation results main models

\begin{tabular}{|c|c|c|c|c|c|}
\hline & First & 2014 effect & UBP effect & Frequency & Technique \\
\hline Only post separation & $6.21 * * *$ & $4.78 * * *$ & $5.85 * * *$ & $5.79 * * *$ & $5.77 * * *$ \\
\hline Extra effect 2014 & - & $3.61 * * *$ & $3.62 * * *$ & $3.00 * * *$ & $3.58 * * *$ \\
\hline With UBP & - & - & 0.01 & -0.02 & -0.06 \\
\hline Only curb separation & $5.56 * * *$ & $4.96 * * *$ & 1.53 & -1.49 & -1.74 \\
\hline Extra effect 2014 & - & $1.92 * * *$ & $1.40 * * *$ & $1.30 * * *$ & $1.33 * * *$ \\
\hline With UBP & - & - & $7.57 * * *$ & $7.25 * * *$ & $7.27 * * *$ \\
\hline Frequency & - & - & - & $0.15^{* * * *}$ & $0.14 * * *$ \\
\hline Only bring separation & 0.33 & 0.71 & -0.22 & -0.21 & -0.23 \\
\hline Extra effect 2014 & - & -0.39 & 0.01 & -0.01 & -0.03 \\
\hline With UBP & - & - & $4.84 * * *$ & $4.77 * * *$ & $4.70 * * *$ \\
\hline Curb and post separation & $8.02 * * *$ & $6.39 * * *$ & $4.82 * * *$ & $4.85 * *$ & $4.74 * *$ \\
\hline Extra effect 2014 & - & $3.37 * * *$ & $2.13 * *$ & $2.09 * *$ & $1.89 * *$ \\
\hline With UBP & - & - & $5.09 * * *$ & $5.07 * * *$ & $5.40 * * *$ \\
\hline Frequency & - & - & - & -0.00 & -0.02 \\
\hline Bring and post separation & $6.51 * * *$ & $4.16^{* *}$ & $3.61 * *$ & $3.57 * *$ & $3.47 * *$ \\
\hline Extra effect 2014 & - & $3.99 * * *$ & $3.23 * * *$ & $3.27 * * *$ & $3.34 * * *$ \\
\hline With UBP & - & - & $3.64 * * *$ & $3.54 * * *$ & $3.52 * * *$ \\
\hline Curb and bring separation & $3.43 * *$ & $3.65^{* *}$ & 1.23 & -0.78 & -1.04 \\
\hline Extra effect 2014 & - & 0.17 & 0.72 & 0.66 & 0.56 \\
\hline With UBP & - & - & $7.14 * * *$ & $6.95 * * *$ & $7.01 * * *$ \\
\hline Frequency & - & - & - & $0.10^{* * *}$ & $0.10^{* * * *}$ \\
\hline Curb, bring and post separation & $7.62 * * *$ & $6.74 * * *$ & $4.62 * * *$ & $4.12 * * *$ & $4.15 * * *$ \\
\hline Extra effect 2014 & - & $2.22 *$ & $2.93 * * *$ & $2.73 * * *$ & $2.66^{* * *}$ \\
\hline With UBP & - & - & $5.85 * * *$ & $5.58 * * *$ & $5.16 * * *$ \\
\hline Frequency & - & - & - & 0.04 & 0.02 \\
\hline Duo-bin & - & - & - & - & $3.04 * *$ \\
\hline Mini-bin & - & - & - & - & $1.65^{* *}$ \\
\hline Crate & - & - & - & - & $1.25 * *$ \\
\hline Household size & $-2.54 * *$ & $-2.33^{*}$ & $-2.41 * * *$ & $-2.29 * * *$ & $-1.70 * *$ \\
\hline Population density & $-0.88 * * *$ & $-0.85^{* * *}$ & $-0.69 * * *$ & $-0.74 * * *$ & $-0.67 * * *$ \\
\hline Inhabitants $65+$ & -0.10 & -0.09 & $-0.11 * *$ & $-0.09 *$ & -0.06 \\
\hline Ethnicity & $-0.26 * * *$ & $-0.25 * * *$ & $-0.15^{* * *}$ & $-0.15^{* * *}$ & $-0.16 * * *$ \\
\hline 2014 & $1.35 * * *$ & - & - & - & - \\
\hline Constant & $16.20 * * *$ & $15.84 * * *$ & $14.98 * * *$ & $14.31 * * *$ & $12.70 * * *$ \\
\hline
\end{tabular}

$* * *, * *, *$ Significance at $99 \%, 95 \%, 90 \%$ levels. Models estimated with VCE Robust estimator

In the first estimation, we compare the different separation systems. ${ }^{11}$ The estimation results show that municipalities with only post separation succeed in separating $6.2 \mathrm{~kg}$

\footnotetext{
11 As a robustness check for the endogeneity of home and post separation dummies we checked whether the total amount of waste per household is different between municipalities with post separation and other municipalities. As this average is almost identical (post separation $518 \mathrm{~kg}$, other municipalities $512 \mathrm{~kg}$ per inhabitant), we conclude that endogeneity is not an issue.
} 
plastic waste per inhabitant. Curbside collection also can be effective, with $5.6 \mathrm{~kg}$ per inhabitant. Only collection by bring locations is clearly not an effective strategy to increase the amount of separated plastic waste. For these municipalities, the estimation of the bring dummy (compared with municipalities with no system) is not significant.

The combination of post separation and curbside collection gives 7.6-8.0 kg per inhabitant. It should be noted that this increase in separated plastic waste compared with the single systems is a rather expensive solution. Interestingly, a combination of curbside collection and bring locations gives a lower amount (i.e. $3.5 \mathrm{~kg}$ ) than only curbside collection (i.e. $5.6 \mathrm{~kg}$ ) This is not in line with Abbott et al. (2017), who show that curbside collection and non-curbside collection are substitutes in case of dry recyclables.

In the second estimation we include a 2014 dummy for different separation systems. While post separation became fully active in the course of 2013, the amount of separated plastic increased from $4.8 \mathrm{~kg}$ in 2013 to $8.4 \mathrm{~kg}(4.78+3.61)$ in 2014. Therefore, the 2014 effectiveness of post separation might be more accurate for evaluating the effect of post separation. Curbside collection also becomes more effective in 2014, but the effect is less than for post separation. This not surprising, as the curbside system has a longer history than post separation. For curbside collection only, this 2014 -effect is $1.9 \mathrm{~kg}$, but if we correct for a UBP system (see third column), an increase in frequency or another type of container for curbside collection, it becomes 1.3-1.4 kg more separated plastic (see third-fifth column).

As shown in the third column of Table 3 , if there is only curbside collection and UBP it follows that the extra amount collected is $7.6 \mathrm{~kg}$. This means that the effect of curbside collection might be much bigger if it is combined with UBP. ${ }^{12}$ If a municipality does not have a UBP system, the effect of curbside collection is not significantly different from zero. If a municipality has only post separation, the effect of a UBP system is not significant different from zero, which gives an indication that the effect of such a system on the reduction of plastic waste through a price incentive is insignificant. So, based on this estimation the effect on packaging plastic of unit-based pricing is small if combined with post separation. Interestingly, for municipalities with only bring locations the effect of having a UBP system is significant, and more than $4.8 \mathrm{~kg}$. Furthermore, if curbside collection is combined with post separation the effectiveness of UBP becomes smaller than $5.1 \mathrm{~kg}$, so it seems that in such a case households are less eager to separate waste. As Halvorsen (2008) shows the willingness to pay for others to recycle depend on income and norms. It might be the case that households are happy to pay the UBP costs and saving on sorting costs as long as they know that their waste is separated.

\footnotetext{
12 Part of the effect of introducing UBP may, however, result from a selection bias or environmental activism. In previous contributions we checked for this effect by estimating an environmental activism dummy (see Dijkgraaf and Gradus 2009). Based on a suggestion of a referee, we include a dummy variable that has the value 1 in all years for each municipality that introduces a unit-based pricing system in our sample period and the value 0 otherwise. If this dummy is significant, it could be the case that municipalities that introduce UBP have already lower waste production because they are greener. For the first two models the dummy is -2.2 and significant, indeed indicating that for these models an environmental activism effect exists. However, if we compare the estimations for the post separation effect with (6.25) and without (6.21) environment activism in the first model they are almost equal. Also for the second model the effects of post separation (in 2014) with (7.99) and without (8.34) are almost equal. Also, for the UBP effect, we find no big difference ( 7.65 with and 7.57 without the activism effect). Thus, we conclude that environmental activism does not influence the main results. Full estimations results are available upon request.
} 
It should be noted that for plastic waste the effects might be dependent on the specific UBP system as plastic is lightweight but bulky. Therefore, the systems based on volume might have a different effect compared with the weight-based system.

So, in cases of home separation a UBP system is needed to increase the amount of plastic waste. In Dijkgraaf and Gradus (2015) we discuss different UBP systems for the Netherlands and their drawbacks. In cities with many flats implementing an UBP system is very difficult. Furthermore, a disadvantage of the bag-based system is that Dutch legislation limits the number of bags carried per waste-collection employee and there is an incentive for households to put as much waste as possible in each bag, which might make them difficult to handle (the so-called Seattle-stomp). In addition, for some Dutch coastal municipalities, there are indications that bags have another disadvantage, as birds such as gulls will cause an extra nuisance by picking through bags. For the weight-based and frequencybased pricing systems, the disadvantages of bags are not present. The introduction of these unit-based pricing systems may, however, have adverse effects as well. The debate on the impact of waste fees on illegal disposal or waste tourism is still open as data are not readily available to test the possible adverse effects.

Furthermore, for curbside collection we add the frequency of collection into the fourth equation. As we would expect, there is a positive relationship between the frequency of collection (except for the combination of curbside collection with post separation) and the quantity of collected plastic waste. However, this effect is rather small. If instead of every 2 weeks once a week plastic waste is collected for curbside only, the amount of plastic waste increases by $3.9 \mathrm{~kg} .{ }^{13},{ }^{14}$ If we also have bring locations, the effectiveness of increasing the frequency becomes smaller: if instead of once a week at the curbside plastic waste are collected every 2 weeks, the amount of plastic waste increases by $2.7 \mathrm{~kg}$.

Also, we do get some significant effects for the type of container. For a crate (compared with a bag) the effect is $1.2 \mathrm{~kg}$ more plastic waste. For duo-bins the effect is especially large, at $3.0 \mathrm{~kg} .{ }^{15}$ However, this could also be partly due to awareness effects as the introduction of duo-bins is often combined with awareness campaigns (of which we do not have detailed information to include it in the estimations explicitly). ${ }^{16}$

In terms of socio-economic variables, we find that three variables are significant (in all equations). First, municipalities with a large household size have less separated plastic waste per inhabitant. This is reasonable as these municipalities have families with more children, so that they have less time to separate plastics. Second, municipalities with a high population density have less separated plastic waste. In these municipalities, the number of apartments seems high and it is more difficult to store plastic waste. Third, municipalities

\footnotetext{
${ }^{13}$ In this case the frequency increases from 26 to 52 , thus the effect is $(52-26) * 0.15=3.9$, with 0.15 the frequency coefficient from Table 1 . We also test for the non-linearity of this frequency variable and we have no indication for that. Those results are available upon request.

14 Similar to Abbott et al. (2011) it is also possible to test the interaction effect with the frequency of collection of unsorted waste. Abbott et al. (2011) show that the lower the frequency of collection of residuals of unsorted waste the higher the recycling rate. In the Netherlands most municipalities collect unsorted waste two-weekly. If, for example, unsorted waste is collected monthly instead of two-weekly, the amount of plastic waste per inhabitant goes up by $0.7 \mathrm{~kg}$, which is still much lower than post-separation or UBP. In line with Dijkgraaf and Gradus (2017) these cross-interactions are not large. Those results can be obtained upon request.

${ }^{15}$ It should be noted that the number of municipalities with a duo-bin (i.e. nine) is rather small, which might bias the estimate.

16 In some (small) Dutch municipalities an awareness campaign started to limit the amount of (mixed) waste per household to $100 \mathrm{~kg}$ yearly and separate several recyclables by duo-bins.
} 
with a larger share of non-western ethnic groups recycle substantially less plastic. This is in line with Abbott et al. (2013), who found that western ethnic groups have a stronger social norm to recycle. For the share of inhabitants above 65 years there is only a significant effect if we correct for the UBP systems.

\section{A Break-Even Point for Post Separation Versus Home Separation}

The question which system is the best is not only dependent on quantity effects, but of course also on costs. Let us assume that in the case of home separation a municipality chooses curbside collection. The costs for curb separation are known. Gradus et al. (2017) show that in 2015 the collection cost of home-separated plastic is on average $€ 408$ per metric ton of plastic. A municipality also receives a compensation fee of $€ 269$ per metric ton of plastic waste for the net treatment costs of transportation and turning the plastic into granules. ${ }^{17}$ This seems rather high according to an international comparison (see Marques and da Cruz 2015), but it should be noted that the Dutch recycling rate for this collected mixed household plastic is only $75 \%$, meaning that $25 \%$ of the collected household plastic is still used for energy recovery (Gradus et al. 2017). Therefore, the quality of this separated mixed plastic is rather low and there is some indication that the quality of plastic by post separation is higher. ${ }^{18}$ Nevertheless, we start with the assumption of similar quality in curb and post separation and later on we relax this assumption. Moreover, we only focus on the monetarized costs and thereby neglect the extra cost of household investment in terms of time spent on separating the waste. ${ }^{19}$

The economic gain when municipalities choose post separation is $€ 348$ per metric ton of plastic in terms of collection costs. ${ }^{20}$ These collection costs can be saved if post separation is applied, as the plastic is then collected together with unsorted waste. Unfortunately, we do not have a good estimation of the cost of the production process of post separation. However, we can calculate what post separation might cost for a break-even between curb and post separation. Table 4 gives this calculation based on the results of Table 3. Hereby, we take the 2014 case as this gives a more accurate description of the effectiveness of post separation.

In Table 4 the weight of separated plastic waste is given per inhabitant in the first row. At the mean, in 2014 , post separation results in $1.50 \mathrm{~kg}$ more separated plastic. The collection costs of both options are included in row two, giving total collection costs per inhabitant in row three of the table. Per kilogram of separated plastic waste, money is saved as the

\footnotetext{
17 Unfortunately, we do not have literature or reports indicating the costs of post separation that is comparable with the separation plants we have in the Netherlands. A summary of separation costs for co-mingled materials (plastic, paper, cardboard, metals) can be found in Plastic ZERO (2013). Based on data for Sweden and France they conclude that sorting costs are between 100 and 200 euro per ton.

18 Hopewell et al. (2009) shows that the quality of recycled plastic can be quite different. As mixed plastic waste can be polluted due to other materials such as food, pigments, inks and adhesives and compression can be an issue. Post separation can give the possibility to select the high-quality recycled plastic as PP and PET better. Moreover, machines are better equipped to do this than people.

19 Kinnaman et al. (2014) show that these costs are rather small compared with collection costs.

${ }^{20}$ Gradus et al. (2017, Table 2) show that the cost of plastic waste collection is $€ 408$ per metric ton, and for mixed waste $€ 60$ per metric ton.
} 
Table 4 Calculation of available resources for post separation

\begin{tabular}{|c|c|c|c|c|c|}
\hline & Post & Curb & Difference 2014 & $\begin{array}{l}\text { Difference } \\
100 \% \text { recy- } \\
\text { cling }\end{array}$ & $\begin{array}{l}\text { Difference } \\
\text { higher } \\
\text { price }\end{array}$ \\
\hline $\begin{array}{l}\text { Weight of separated plastic per inhabitant } \\
(\mathrm{kg})^{\mathrm{a}}\end{array}$ & 15.20 & 13.70 & 1.50 & 1.50 & 1.50 \\
\hline Collection costs $\left(€\right.$ per kg) ${ }^{\mathrm{b}}$ & 0.06 & 0.41 & -0.35 & -0.35 & -0.35 \\
\hline Collection cost per inhabitant $(€)$ & 0.89 & 5.46 & -4.57 & -4.57 & -4.57 \\
\hline $\begin{array}{l}\text { Savings on virgin material and energy }(€ \\
\text { per } \mathrm{kg})^{\mathrm{c}}\end{array}$ & 0.19 & 0.19 & 0.00 & 0.00 & 0.00 \\
\hline $\begin{array}{l}\text { Savings virgin material and energy per } \\
\text { inhabitant }(€)\end{array}$ & 2.86 & 2.57 & 0.29 & 0.34 & 0.41 \\
\hline Net costs per inhabitant $(€)$ & -1.97 & 2.89 & -4.86 & -4.91 & -4.98 \\
\hline $\begin{array}{l}\text { Available for post separation per inhabitant } \\
(€)\end{array}$ & & & 4.86 & 4.91 & 4.98 \\
\hline $\begin{array}{l}\text { Available for post separation per metric ton } \\
(€)^{\mathrm{d}}\end{array}$ & & & 320 & 323 & 327 \\
\hline
\end{tabular}

${ }^{\text {a }}$ To calculate the quantity of plastic for post and curb separation we take the mean for all explaining variables multiplied by the coefficient with the constant and respectively the post and curb dummy at value 1 . This is based on the 2014-estimation in Table 3 and the mean's in Table 2

${ }^{\mathrm{b}}$ See Gradus et al. (2017)

${ }^{\mathrm{c}}$ Value of virgin plastic minus treatment costs and opportunity costs of separated plastic; see Gradus et al. (2017)

${ }^{\mathrm{d}}$ This is calculated as $(1000 / 15.20) *$ Available for post separation per inhabitant

production costs of virgin material according to Gradus et al. (2017) (€495 per metric ton) are higher than the treatment costs for recycled plastic ( $€ 269$ per metric ton of separated plastic). Combining the first row with these net savings ( $€ 226$ per metric ton) gives total savings per inhabitant. Adding the third row to the fifth row gives net costs in euros per inhabitant. This means that per inhabitant, $€ 4.86$ are saved if post separation is chosen. This $€ 4.86$ can be spent to collect the quantity of $15.20 \mathrm{~kg}$, resulting in available savings of $€ 320$ per metric ton of plastic. ${ }^{21}$ Thus, if the (yearly) costs of separating plastics from unsorted waste are below $€ 320$ per metric ton, post separation should be chosen from an economic perspective.

Furthermore, there are indications that post separation should be chosen from an economic perspective. In 2018, an agreement was made between Afvalfonds and waste-toenergy plant (AEB) for the city of Amsterdam. AEB builds a new plant for industrial or post separation of plastic waste. Importantly, in their press-release they announced: "That means lower fees, and long-term security" (Afvalfonds 2017). However, exact information is lacking due to the confidentiality of these figures. Remarkably, the city of Amsterdam announced that it goes for a combination of post and home collection, and as a result the extra quantity of post separated plastic is minimal. However, due to problems by its waste management company, i.e. AEB, Amsterdam later on announces it will go for post

$\overline{21}$ For the technique model this threshold becomes $€ 338$ per metric ton. 
separation. Moreover, Rotterdam opened its factory in 2019 and stopped end 2019 with home separation. For this large city there is circumstantial evidence that the amount of plastic is much higher by post separation. In addition, there is some evidence that the quality and the revenues of recycled plastic waste is better in case of post-separation than by home-separation. Post separation makes it possible to collect plastics with a longer lifespan (for instance household utensils, construction plastics and toys) (see also Feil et al. 2017). Moreover, Brouwer et al. (2018) shows that post separation generates lower polymeric contamination of sorted plastics as PET, PE, PP, film and Mix than home separation. Finally, post separation avoids the separate collecting of low-quality mixed plastics, which normally are burned and therefore these costs are saved.

Based on this evidence, we calculate two different scenarios based on a better quality of post-separated plastic. In the first scenario all separated plastic waste is recycled instead of $75 \%$. In that case the savings on virgin material go up and become $€ 0.34$ per inhabitant and the threshold becomes $€ 323$. If we assume that the price of secondary plastic will rise by $10 \%$, from $€ 495$ to $€ 544$ per metric ton due to better quality, this threshold becomes $€ 327$. In both cases the threshold price is even higher. Summarizing, if the separation costs are lower than $€ 326$ per metric ton of plastic, the post separation model should be chosen from an economic point of view. There are indications that the costs of a modern plant are lower.

\section{Conclusions}

By analyzing Dutch municipal data for plastic recycling for 2013-2014, there are serious questions about the politically preferred solution of home collection schemes as post separation yields more kilogram separated plastic per inhabitant. Municipalities with only post separation succeed in separating $6.2 \mathrm{~kg}$ more plastic waste per inhabitant than those without plastic waste separation. As in the course of 2013 post separation became active in most municipalities, the 2014 effect was also estimated, and the amount of separated plastic increased to $8.4 \mathrm{~kg}$. To give the best estimate for the effectiveness of this post-separation system, the last figure is more accurate. Separating plastics by only curbside collection also can be effective, with almost $7 \mathrm{~kg}$. Collection by only bring locations is not a very effective strategy to increase the amount of recycled plastic waste.

For curbside collection, we test also the interaction effects with a unit-based pricing system, frequency of collection and type of container. The combination of curbside collection with UBP gives an extra amount of $7.6 \mathrm{~kg}$ somewhat less than post separation. Increasing the frequency of curbside collection of plastics is less effective. If curbside collection is combined with post separation the effectiveness of UBP becomes smaller, or in the case of a high frequency of collection even not significantly different from zero. There are some municipalities which go for a combination of post-separation and curbside collection, but as our estimates suggest this is not advisable from a cost and environmental point. Furthermore, we test the interaction effect of post separation with UBP. As this effect is not significant, this gives an indication that the awareness effect of such a system on reduction of plastic waste through price incentives is insignificant. D'Amato et al. (2016) indicate that only those who are more highly educated are motivated to change their recycling behavior, 
which is in accordance with our results, although it was not tested directly. Heller and Vatn (2017) suggest that a price incentive even can have adverse effects for certain groups. The overall conclusion of this research is that municipalities should choose between post-separation and home-separation combined with a UBP system. Other combinations seem not advisable.

Although we do not have information about the total costs of post separation, there are indications that the cost effectiveness will increase if post separation is chosen. The collection costs are much lower as plastic waste is collected as part of mixed waste. We calculate that if the separation costs are lower than $€ 326$ per metric ton of plastic, post separation is the cost-effective solution. This threshold increases if one considers that the quality of secondary plastic and the price of plastic increases if post separation is chosen. Feil et al. (2019) show that innovations in post separation can be helpful to raise the amount and yield of recyclable plastic.

In the Netherlands home separation of plastic waste by curbside collection is the most implemented policy. If home separation is chosen, it seems advisable to combine it with UBP to increase the quantity of plastic. However, UBP systems can have some drawbacks as well. It should be noted that especially in large cities with many flats implementing a UBP system is very difficult. In Dijkgraaf and Gradus (2015), we compare different UBP systems in the Netherlands and show that bag-based and weightbased systems have some drawbacks, and the frequency-based system is preferred. Nevertheless, UBP systems can be used in small municipalities. However, for cities with many flats it will be harder to implement as there is no place to store the recyclables. At least in cases where UBP is not implemented, post separation is a good alternative, also due to the fact that it has the potential of increasing effectiveness over time. For home separation this will be more difficult. Therefore, we advise that the European Directive on plastic packaging should be amended in such a way that post separation can be an alternative for home separation.

There are many avenues to explore in future research. First, it is important to test whether the effectiveness of post separation also increases in later years. Unfortunately, more recent information about separation methods is not available yet. Second, cost information about post separation is important to understand the overall cost effectiveness of this process. Hereby, as pointed out in the sensitivity analysis in Sect. 4, the increase in quality of recycled plastic waste as a consequence of post separation should be taken into account (see also Brouwer et al. 2009, 2018). There is some evidence for this as shown by a recent agreement between Afvalfonds Verpakkingen and the city of Amsterdam, but a sound empirical investigation is lacking. Third, as home separation is only advisable if it is combined with UBP, the drawbacks of pricing systems should be better investigated. Especially, the issue of illegal or illicit dumping is important. Therefore, we encourage to gather more data on illegal dumping.

Acknowledgements The authors would like to thank two anonymous referees, Tjaco Twigt and Coen Bertens of Afvalfonds Verpakkingen for comments on an earlier draft. The views in the paper are the authors' own. 
Open Access This article is licensed under a Creative Commons Attribution 4.0 International License, which permits use, sharing, adaptation, distribution and reproduction in any medium or format, as long as you give appropriate credit to the original author(s) and the source, provide a link to the Creative Commons licence, and indicate if changes were made. The images or other third party material in this article are included in the article's Creative Commons licence, unless indicated otherwise in a credit line to the material. If material is not included in the article's Creative Commons licence and your intended use is not permitted by statutory regulation or exceeds the permitted use, you will need to obtain permission directly from the copyright holder. To view a copy of this licence, visit http://creativecommons.org/licenses/by/4.0/.

\section{Appendix: Definition of Variables}

\begin{tabular}{|c|c|}
\hline Plastic waste & Separately collected plastic waste in kilogram per inhabitant \\
\hline Household size & Number of inhabitants per household \\
\hline Population density & Municipal area in square kilometers per household \\
\hline Inhabitants $65+$ & Share of inhabitants older than 65 \\
\hline Ethnicity & $\begin{array}{l}\text { Share of non-western people (born in or parents from a non-western } \\
\text { country) in total number of inhabitants }\end{array}$ \\
\hline UBP: Volume & Dummy is 1 if volume-based pricing system is present and 0 otherwise \\
\hline UBP: Frequency & Dummy is 1 if frequency-based pricing system is present and 0 otherwise \\
\hline UBP: Bag & Dummy is 1 if bag-based pricing system is present and 0 otherwise \\
\hline UBP: Weight & Dummy is 1 if weight-based pricing system is present and 0 otherwise \\
\hline Frequency curbside & Number of times a year plastic waste is collected at the curbside \\
\hline Duo-bin & Dummy is 1 if plastic waste is collected at the curbside from a duo-bin \\
\hline Mini-bin & Dummy is 1 if plastic waste is collected at the curbside from a mini-bin \\
\hline Bag & Dummy is 1 if plastic waste is collected at the curbside from a bag \\
\hline Crate & Dummy is 1 if plastic waste is collected at the curbside from a crate \\
\hline 2014 & Dummy is 1 for observations in 2014 \\
\hline
\end{tabular}

\section{References}

Abbott A, Nandeibam S, O'Shea L (2011) Explaining the variation in household recycling rates across the UK. Ecol Econ 70(11):2214-2223

Abbott A, Nandeibam S, O’Shea L (2013) Recycling: social norms and warm-glow revisited. Ecol Econ 90:10-18

Abbott A, Nandeibam S, O'Shea L (2017) The displacement effect of convenience: the case of recycling. Ecol Econ 136:159-168

Afvalfonds Verpakkingen (2017) Afvalfonds Verpakkingen en AEB Amsterdam tekenen intentieovereenkomst voor optimalisatie en verduurzaming recycleketen. Press release January 10

Brouwer M, Thoden van Velzen EU, Augustinus A, Soethoudt H, De Meester S, Rageart K (2018) Predictive model for the Dutch post-consumer plastic packaging recycling system and implications for the circular economy. Waste Manag 71:62-85

Carattini S, Baranzini A, Lalive R (2018) Is taxing waste a waste of time? evidence from a supreme court decision. Ecol Econ 148:131-151

D'Amato A, Mancinelli S, Zoli M (2016) Complementarity vs sustainability in waste management behaviors. Ecol Econ 123:84-94

Dijkgraaf E, Gradus RHJM (2009) Environmental activism and dynamics of unit-based pricing. Resour Energy Econ 31(1):13-23

Dijkgraaf E, Gradus RHJM (2014) Waste management in the Netherlands. In: Kinnaman T, Takeuchi K (eds) Handbook on waste management. Edward Elgar Publishers, Cheltenham, pp 287-315 
Dijkgraaf E, Gradus RHJM (2015) Efficiency effects of unit-based pricing systems and institutional choices of waste collection. Environ Resour Econ 61(4):641-650

Dijkgraaf E, Gradus RHJM (2017) An EU recycling target: what does the Dutch evidence tell us? Environ Resour Econ 68(3):501-526

EC (2017) Council and Parliament reach provisional agreement on new EU waste rules. www.wwwconsili umeuropaeu/en/press/press-releases/2017/12/18/council-and-parliament-reach-provisional-agreementon-new-eu-waste-rules/. Accessed 25 Feb 2018

Erhardt T (2019) Garbage in and garbage out? On waste havens in Switzerland. Environ Resour Econ 73(1):251-282

Feil A, Pretz T, Jansen M, Thoden van Velzen U (2017) Separate collection of plastic waste better than technical sorting from municipal solid waste? Waste Manag Res 35(2):172-180

Feil A, Coskun E, Bosling M, Kaufeld S, Pretz T (2019) Improvement of the recycling of plastics in lightweight packaging treatment plans. Waste Manag Res 37(2):120-126

Fullerton D, Kinnaman TC (1996) Household responses to pricing garbage by the bag. Am Econ Rev 86(4):971-984

Gradus RHJM, Dijkgraaf E (2019) Poorer and less political fragmented Dutch municipalities take tighter waste reduction decisions. Waste Manag 88(3):328-336

Gradus RHJM, Nillesen P, Dijkgraaf E, Van Koppen R (2017) A cost-effectiveness analysis for incineration or recycling of Dutch household plastic waste. Ecol Econ 135:22-28

Halvorsen B (2008) Effects of norms and opportunity costs of time on household recycling. Land Econ 84:501-516

Heller M, Vatn A (2017) The divisive and disruptive of a weight-based waste fee. Ecol Econ 131:275-285

Hopewell J, Dvorak R, Kosior E (2009) Plastics recycling: challenges and opportunities. Philos Trans R Soc B Biol Sci 364:2115-2126

Kennisinstituut Duurzaam Verpakken (KIDV), Natuur\&Milieu, CE Delft (2016) Factsheet plastic recycling. Den Haag, March 22

Kinnaman TC, Shinkuma T, Yamamoto M (2014) The socially optimal recycling rate: evidence from Japan. J Environ Econ Manag 68(1):54-70

Marques RC, Da Cruz NF (2015) Recycling and extended producer responsibility: the european experience. Ashgate, Dorchester

Nichols A, Schaffer M (2007) Clustered errors in Stata. www.wwwstatacom/meeting/13uk/nichols_crsepdf. Accessed 2 May 2017

Plastic ZERO (2013) Report on assessment of, City of Copenhagen, City of Malmö, City of Hamburg, SIA Liepajas RAS, I/S Amager Ressourcecenter, Tampere Regional Solid Waste Management Ltd., Aalborg University, LIFE10 ENV/DK/098 relevant recycling technologies-Public Private Cooperations for Avoiding Plastic as a Waste

Publisher's Note Springer Nature remains neutral with regard to jurisdictional claims in published maps and institutional affiliations. 